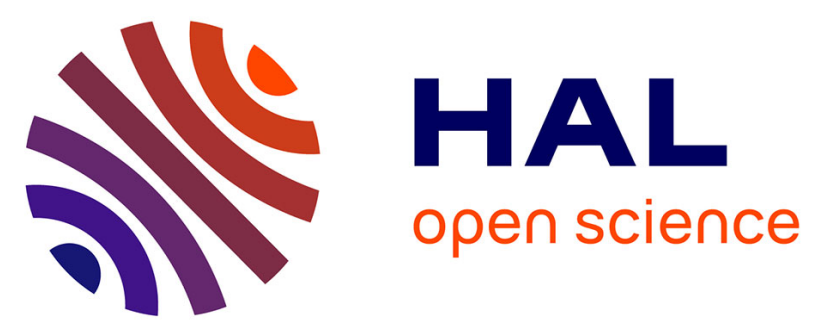

\title{
Experimentation of Cross-Border Digital Innovation Hubs (DIHs) Cooperation and Impact on SME Services
}

\author{
Margherita Volpe, Omar Veledar, Isabelle Chartier, Isabelle Dor, Fredy Ríos
}

Silva, Jure Trilar, Csaba Kiraly, Gabriele Gaffuri, Sabine Hafner-Zimmermann

\section{- To cite this version:}

Margherita Volpe, Omar Veledar, Isabelle Chartier, Isabelle Dor, Fredy Ríos Silva, et al.. Experimentation of Cross-Border Digital Innovation Hubs (DIHs) Cooperation and Impact on SME Services. 22nd Working Conference on Virtual Enterprises (PRO-VE 2021), Nov 2021, Saint-Etienne, France. pp.423-432, 10.1007/978-3-030-85969-5_39 . emse-03346027

\section{HAL Id: emse-03346027 \\ https://hal-emse.ccsd.cnrs.fr/emse-03346027}

Submitted on 25 Nov 2021

HAL is a multi-disciplinary open access archive for the deposit and dissemination of scientific research documents, whether they are published or not. The documents may come from teaching and research institutions in France or abroad, or from public or private research centers.
L'archive ouverte pluridisciplinaire $\mathbf{H A L}$, est destinée au dépôt et à la diffusion de documents scientifiques de niveau recherche, publiés ou non, émanant des établissements d'enseignement et de recherche français ou étrangers, des laboratoires publics ou privés. 


\title{
Experimentation of Cross-Border Digital Innovation Hubs (DIHs) Cooperation and Impact on SME Services
}

\author{
Margherita Volpe ${ }^{1}$, Omar Veledar ${ }^{2}$, Isabelle Chartier ${ }^{3}$, Isabelle Dor ${ }^{3}$, Fredy Ríos Silva ${ }^{4}$, Jure \\ Trilar $^{5}$, Csaba Kiraly ${ }^{6}$, Gabriele Gaffuri ${ }^{1}$, Sabine Hafner-Zimmermann ${ }^{4}$ \\ ${ }^{1}$ Zabala Innovation Consulting, Brussels, Belgium \\ ${ }^{2}$ AVL List GmbH, Graz, Austria \\ ${ }^{3}$ Université Grenoble Alpes, CEA, Leti, F-38000, Grenoble, France \\ ${ }^{4}$ Steinbeis Europa Zentrum, Karlsruhe, Germany \\ ${ }^{5}$ University of Ljubljana, Ljubljana, Slovenia \\ ${ }^{6}$ Digital Catapult, London, UK
}

\begin{abstract}
As digital transformation imposes cultural changes in terms of how value is delivered, continual experimentation helps define optimal solutions for key stakeholders. From the DIH perspective, the hunt is on for the most impactful and financially sustainable services that lend themselves to practical customisation against target group needs. Among these, fostering cross-border collaboration amongst themselves and between SMEs is also a desirable, albeit challenging strategy to be pursued by DIHs. We present the approach of DigiFed (European Commission funded project), which relies on a network of 12 DIHs and Research Technology Organisations (RTOs) to design and experiment with novel innovation support mechanisms for SMEs across Europe. We analyse the currently implemented cross-border cooperation instruments and their preliminary results and describe additional instruments under ongoing experimentation. We also elaborate on prospects to generalise these instruments for adoption by other DIH networks.
\end{abstract}

Keywords: DIH network, collaborative methods, innovation support, Application Experiments, cross-border collaboration, SMEs

\section{Introduction}

The experimentation of tools and collaborative services that are offered by DIHs is a matter of interest at the national and European level. The offered support occasionally benefits from the opportunities presented by European Commission's (EC) R\&I funding programmes. This is the case of DigiFed - Digital Innovation Hubs (DIH) federation for large scale adoption of digital technologies by European SMEs, which is currently experimenting with different pathways to foster cross-border collaborative innovation, primarily among SMEs. The paper discusses the currently implemented cross-border cooperation instruments and their preliminary results, as a contribution to the investigation of collaborative services and success stories among DIHs.

To maximise the benefits of digital innovations for European industries, the EC is realising its Digitising European Industry (DEI) Strategy [1]. It focuses on upgrades of 
assets and processes, and business models adaptation to the digital age. This calls for the full integration of digital innovations across all economic sectors. One of DEI's key elements is DIH. These hubs support Small and Medium Enterprises (SME), start-ups and mid-caps in boosting their competitive advantage by fostering the adoption of the latest digital technologies. Acting as a one-stop-shop, they provide access to digital technologies and competence, infrastructure to test digital innovations, training to develop digital skills, financing support, market intelligence and networking opportunities. The EC invests in EU-wide collaboration across the network of DIHs. What started in 2013 with the ICT Innovation for Manufacturing SMEs (I4MS) initiative [2], was followed by the Smart Anything Everywhere initiative (SAE) in 2015 [3]. The SAE covers different projects, involving DIHs throughout Europe, in several technology areas, including Cyber-Physical Systems (CPS) and Embedded Systems. All projects offer so-called cascade funding to SMEs and mid-caps to enhance their assets through the inclusion of innovative digital technologies. The expectation is for the selected projects to achieve technical maturity worthy of sustainable introduction to the market, as also reported by others [4]. By improving digital maturity levels, DigiFed also leverages created solutions to enable new use cases and services in an industrial context. Hence, the focus is placed on successfully formulating and implementing go-to-market strategies based on expressed customer needs. Such an approach is critical for customer-driven innovation [5].

EC has financed 16 projects under the umbrella of SAE. Besides aiding industrial digitalisation, these projects open new markets enabled by CPS and embedded systems. One of those projects is DigiFed, which was launched in January 2020. Its objectives include supporting the digitalisation of companies, enhancing DIH services offer, improving collaboration among DIHs and experimenting with new funding schemes to support the digital transformation of European companies. The consortium currently gathers the following DIHs: Minalogic, France; Ikerlan, Spain; Digital Catapult, UK; and Steinbeis, Germany. All DIHs work with and enhance cooperation within established ecosystems, expanding and linking with other networks to create an EUwide Federation of DIHs. These DIHs offer sustainable cross-border services and partnerships between relevant European innovation stakeholders (e.g. research \& technology organisations (RTOs), Universities, Accelerators, etc.). To that purpose, the project implements 3 interrelated innovation pathways: Application Experiment (AEs), Generic Experiment and Digital Challenge.

AEs are at the core of DigiFed. This pathway attracts companies with varying digital maturity levels. Those with low digital maturity are supported in upgrading existing products and skills with dedicated services, tools and solutions. Digitally mature companies are offered further innovative technology integration and access to potential customers, including large industrial stakeholders. AEs have proven their worth through several initiatives, especially in the cases of I4MS and SAE

This paper contributes to the research question "How DIHs can effectively foster cross-border collaboration among each other and between private companies?" by describing the toolbox of services implemented within DigiFed project and by analysing the evaluation results and success rate of collaborative projects (TWIN AE) against those that are originating from individual organisations (SINGLE AE) at the application stage. The analysis facilitates the assessment of the potential of such supporting instruments to effectively promote and foster cross-border collaboration. 
The paper also attempts to identify if DigiFed's support infrastructure could serve as a portable example of DIH collaboration to foster similar cross-border partnerships between SMEs and midcaps across Europe to achieve increasing returns through innovation enticed by cross-border cooperation, as reported in [6].

Open Calls for Application Experiments. AE is a cascade funding pathway that selects and finances SMEs and mid-caps to develop CPS solutions based on existing or to-be-developed prototypes and products. The selection process is initiated via public open calls and obeys the EC's principles of transparency, confidentiality, equal treatment, and avoidance of conflict of interests. Applicants may apply via two different configurations:

> Single $A E$ : a company requests funding (maximum $€ 55 \mathrm{k}$ ) for an exclusive collaboration with one cross-border DigiFed technical partner, which is selected by the applicant based on a portfolio of technological offerings.

$>$ Twin $A E$ : two SMEs or mid-caps jointly apply for maximum funding of $€ 55 \mathrm{k}$ per applicant, while respecting the cross-border eligibility criteria.

The experience acquired through innovation actions, such as EuroCPS [7] and FED4SAE [8], suggests that the SINGLE AE type is better adapted to the needs of organisations that are already engaging digital technologies or wish to integrate new digital technologies and increase digital maturity. TWIN AE is already tested in a slightly different form by other SAE innovation actions, such as Tetracom [9] or Tetramax [10]. While also open to companies with a high digital maturity level, TWIN AE attracts "non-digital" applicants that wish to create the first product/service demonstrator based on digital technologies. TWIN AE fosters the collaboration of companies that aim to further CPS-based innovation and have a clear market vision but lack expertise to validate the concept with companies that bring the complementary expertise to realise the prototype or directly access the market.

The two AE types are evaluated through the same evaluation process using the same scoring criteria (i.e. business development potential, excellence, impact and quality of implementation). They are also ranked in a unified evaluation list. The top-scoring applications are selected for financing. To ensure the maximum possible transparency and equal treatment of all applicants, each proposal is evaluated in parallel by 3 external independent experts and a panel of DigiFed internal evaluators, generating an aggregated scoring list. Considering that no AE type is favoured (i.e. there is no minimum guaranteed number of SINGLE or TWIN AEs to be funded), the emerging results from two open calls (OC) provide insights into the success of each AE type.

\section{Support Provided by DIHs to Open Call Applicants}

The described OC organisation and management is complemented by specific actions aimed at supporting AEs in their creation, application, implementation and sustainable exploitation. The crucial support at the creation phase often helps to form the basis for sustainable collaboration. The initial support considers two basic aspects:

> The eligibility criteria are clarified to potential applicants at the start of the process. 
$>$ Proposal creation- support guidance identification of the project's crucial aspects and their mapping to the requirements of the proposal. Aside from the benefit for the applicants to gain experience with the proposal writing, this process also fosters improvement in the realistic estimation of the project's scope, time and budget.

This support takes several forms, including self-service materials (e.g. guide for applicants, detailed application template), an online application platform (including Frequently Asked Questions, information helpdesk), and interactive sessions. As concerns the latter, the following formats have been implemented:

$>$ Webinars with a focus on specific application aspects are also recorded and provided as a YouTube video reference for further self-help. An example includes business pitch video guidelines. The pitch replaces the originally planned short interviews with the applicants. In order to optimise the effectiveness of the process and reduce the time needed to process the relevant amount of applications expected and actually received, the pitch enables the applicants to present their value creation concisely.

$>$ Bootcamps represent an opportunity to discover DigiFed's technology and innovation management offer, while also enabling applicants to meet prospective partners (i.e., a form of matchmaking).

The support is geared towards the creation of structured proposals through dialogue that encourages applicants to question their own ideas. Thus, the selection process distinguishes the most promising AEs. Further support aids the creation of TWIN projects through several matchmaking opportunities for the prospective partners. Where applicable, DigiFed also facilitates dialogue between those partners to perfect a common offer. The complete process, together with the monitoring of the selected AEs, aims at the sustainable success of the generated assets in the post-AE phase.

\section{Application Experiment Analysis and Discussion}

The effectiveness of the DigiFed AE pathway is based on statistical evaluation (basic distribution and dispersion analysis) of the results achieved so far. the outcome of the analysis is interpreted using the direct experience of the authors in the implementation of the DigiFed project and interaction with the involved beneficiaries, in a living-lablike approach. OC1 (active from March to June 2020) received 72 eligible proposals, submitted by 94 companies from 26 (EU and associated) countries. They ranged from start-up to mid-cap size, with an expected prevalence of smaller applicants, i.e. start-up and SMEs up to 10 employees representing $72 \%$ of applicants. After the implementation of the selection process, OC1 resulted in 14 projects selected for funding and 22 companies receiving a total of over $€ 1.1$ million for digital innovation. OC1 served as an experiment to assess the reception and application capability of EU companies concerning different collaboration requirements of SINGLE and TWIN AEs. These instruments were well received as OC1 resulted in over 90 companies applying and a total of 48 Single AE and 24 TWIN AE proposals received.

OC2 (launched in September 2020 and closed in December 2020) received a total of 75 proposals from 96 companies originating from $25 \mathrm{EU}$ and associated states. The application rate per AE type was again fairly - and even better- balanced, with 32 SINGLE AE and 43 TWIN AEs eligible for evaluation. Once again, there was a clear 
prevalence of applicants from smaller companies (i.e. 28\% start-up, 48\% SME 1-10 employees), confirming the trend observed in OC1. OC2 resulted in 16 proposals selected for funding, which involved a total of 25 companies.

These initial data on application rates raised two indications:

$>\mathrm{AE}$ is confirmed to be particularly appealing to smaller companies,

> Despite being in its experimental stage, the cross-border aspect of the TWIN AE type is confirmed to be an interesting approach for collaboration amongst peers in the framework of a financed research \& innovation project.

Upon confirming the appeal of the TWIN AE, the following step was to understand whether the TWIN AE proposals were also successful in the selection process. The evaluation process data indicate not only that TWIN AEs were equally represented among selected AE, but their evaluation scores were also on average higher than those of SINGLE AEs. Table 1 displays the comparison of the TWIN and SINGLE AE success rates for both OCs, with 14 and 16 proposals being selected, respectively. The initial observation is that the final proposal ranking for both OCs generates a fairly balanced ratio between the two $\mathrm{AE}$ types.

Table 1 Success rate at the application stage

\begin{tabular}{l|lll}
\hline & TOTAL SELECTED & TWIN AE & SINGLE AE \\
\hline OC1 & $14(100 \%)$ & $6(43 \%)$ & $8(57 \%)$ \\
OC2 & $16(100 \%)$ & $7(44 \%)$ & $9(56 \%)$ \\
\hline
\end{tabular}

Yet, to define the relevance of these data or their bias by a higher application rate in one or the other cluster, the number of selected proposals was compared to the number of applications submitted per each AE type to determine the actual success rate, corresponding to the ratio between awarded and submitted proposals per type. This resulted in divergent trends between two OCs, as the success rate per AE type was:

$>\mathrm{OC} 1 \rightarrow$ Twin $\mathrm{AE} 33 \%$ success rate vs. Single AE $13 \%$ success rate

$>\mathrm{OC} 2 \rightarrow$ Twin AE $16 \%$ success rate vs. Single AE $26 \%$ success rate

Nevertheless, further data analysis (Table 2) suggests that smaller companies had a consistently higher success rate when applying within the TWIN AE configuration rather than in a SINGLE AE; suggesting that this instrument is particularly apt to aid the major target audience and smaller companies (as per DIH mission).

Table 2 Success rate with respect to the company size

\begin{tabular}{l|cc|cc}
\hline & Start-ups & \multicolumn{2}{|c}{ SME 1-10 employees } \\
\cline { 2 - 5 } & TWIN AE & SINGLE AE & TWIN AE & SINGLE AE \\
OC1 & success rate & success rate & success rate & success rate \\
OC2 & $23 \%$ & $25 \%$ & $16 \%$ & $5 \%$ \\
\hline
\end{tabular}

The analysis of the evaluation scores per AE type is visualised in Figure 1. The distribution of the scores of all the applicants in each of these categories per OC shows a general tendency of a higher scoring of TWIN over SINGLE AEs, albeit without a 
strong dominance. If focusing only on the call winners, the dispersion of the scores is reduced. However, a soft dominance of TWIN AEs is present.

The total score per application is also analysed. The score is obtained by simply adding the scores in the four criteria. A clearer dominance of TWIN AE is observable, especially if only focusing on the winners of $\mathrm{OC} 2$. A difference is also observed in TWIN AEs between the two OCs. In this case, the dispersion of the scores drastically increases for winners, as well as overall applicants. A possible explanation could be related to the fact that SINGLE proposals were being more comprehensively guided by the DigiFed technical partners, hence containing the dispersion of scores. The in-depth investigation of this aspect exceeds the scope of this paper and will be the object of further analysis.

Hence, the analysed data suggest that the TWIN AE was an effective tool to boost cross-border collaboration among peers, and, mostly among smaller companies, in line with the mission of DIHs. Further information elaborated at the qualitative level suggests added relevant impacts. First, it has been noticed that TWIN AEs were particularly suitable to promote the participation of low digital companies. Indeed, based on the direct interactions that the DigiFed monitoring partners had with the applicants during the $\mathrm{OC} 1$ implementation phase and during the helpdesk sessions, a qualitative trend of low digitalised companies' participation predominantly in TWIN AEs was appreciated. For this reason, a first assessment tool was introduced in OC2, based on a single question asked to all the applicants during the registration phase (for preliminary characterisation of the applicant population). The results of this test confirmed the fact that, among low digital maturity companies (13\% of the total OC1 and OC2 applicants), two thirds applied as TWIN AE. Indeed, the number of applicants with low digital maturity has been twice as high in TWIN AEs than in SINGLE AEs. Based on the preliminary evidence, DigiFed is experimenting in its third OC with a specific AE type aimed at increasing the participation of low digital maturity companies and is working in parallel on an extended structure of digital maturity assessment and impact estimation (see section 4). The complex issues of assessing the maturity level of SMEs [11] is simplified to the level adequate for implementation within DigiFed. Secondly, based on a brief online survey addressed to all awarded TWIN AE beneficiaries, it has been noted that this AE type is also functional to support the business of the applicants. Most respondents (66,7\%) confirmed that the TWIN AE allowed them to consolidate ongoing collaboration partnerships and that the expected benefits of this collaboration encompass the complementarity of competences, the consolidation of long-lasting collaborations and the possibility to enter new markets. 


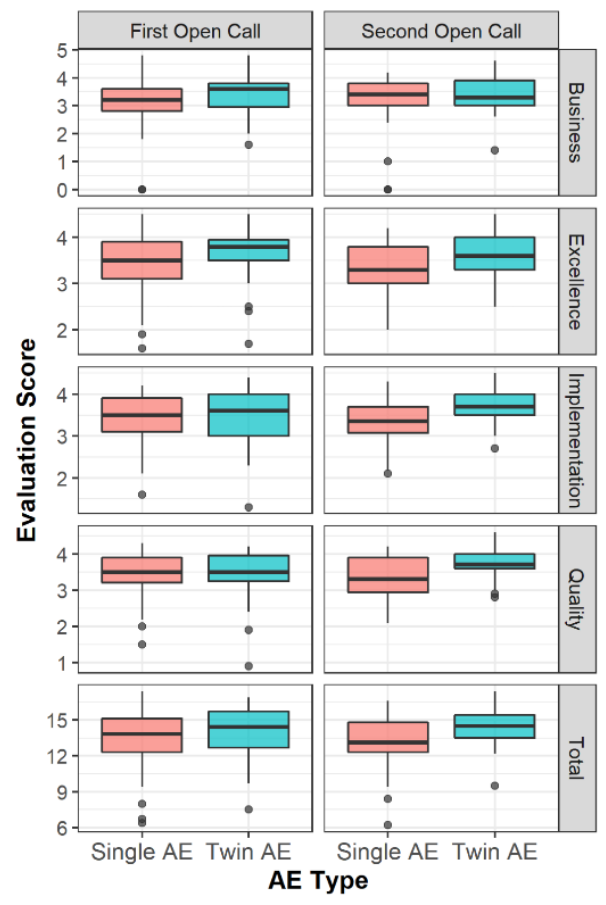

a. Scores of all applicants

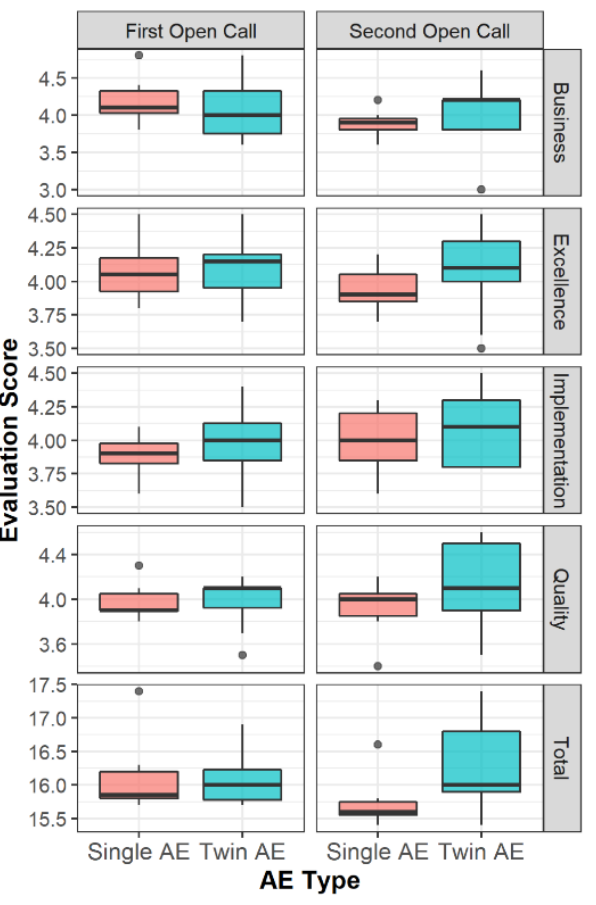

b. Scores of the winners

Figure 1. Distribution of the scores of applicants and winners of both DigiFed OCs according to the different evaluation criteria and the total score

\section{Other Collaborative Actions}

Although the TWIN AE instrument is the key mechanism of fostering cross border [12, 13] technical and business innovation amongst SMEs [14] through cascade fundingsupported projects, DigiFed is experimenting with other variants of similar engagement. The other variants are not presented in detail here, but we will further explore recognisable topological features of these instruments to provide improved understanding and potential reuse in DIHs and collaborative scenarios.

Three other instruments had been developed to foster the close-knit cross-border cooperation, taking a different angle on how the projects could be formed:

Dow-digital TWIN AE (conceived based on the evidence discussed above) targeting asymmetric scenarios with one SME as a technology provider that integrates innovative concepts into the environment of a low digital maturity SME in another country. Funding up to $€ 50 \mathrm{k}$ is offered for each applicant. 
Digital Challenge is another asymmetric scheme, where a large enterprise (Digital Challenge Owner) acts as an early adopter seeking cutting-edge digital solutions to a defined challenge. The purpose is to highlight attractive market needs to be addressed through CPS and embedded systems to solve industry challenges set by corporate stakeholders. The mechanism is applied where no available solutions have been identified in the market and the proposed solutions are to be developed and integrated into their core processes by the selected SME. The financial support of the Digital Challenge Owner to SME is matched by DigiFed (up to $€ 55 \mathrm{k}$ ).

$>$ Generic Experiment (GE), distinguished from the others by the active technology support to SMEs from the coordinating facility (DIH or otherwise) with a technological research and development function. In particular, GE revolves around key-enabling technology building blocks which the cascade funding coordinator develops through exploration of the international market and valuechain requirements. This inquiry is conducted with SMEs participating in the GE community through various activities, e.g., workshops to implement advanced technology demonstrators with co-funding from regional authorities.

The variants are not necessarily mutually exclusive. They can complement one another e.g.; an AE project might result in an innovative solution that can be later integrated into a Digital Challenge. Overcoming differences in business culture yields direct benefits for the future endeavours of the involved SMEs. The general benefits for participants involve cross-border collaboration through administrative rules of cascade funding, improved funding and networking opportunities, access to knowledge and equipment, a better understanding of foreign markets and transferability potential, possible staff exchange etc. There is also a major benefit of customised schemes of cofunding and scale of funding coordinator involvement to provide distinct results based on resources and objectives of DIHs. European DIHs strive to engage more actors to increase coverage of industrial sectors and widen own networks for future opportunities [15]. Thus, quick transferability and replicability are essential for paced implementation to support these common goals [16]. In our assessment, the $\mathrm{AE}$ cascade funding instrument with a focus on cross-border cooperation is portable to other ecosystems. Sustainability potential, transferability in other DIH potential, adaptability to context variation and common approaches, balancing flexibility and control, external collaboration [17] within new and established innovation mechanisms, are to be further investigated in a longer and more diversified scenario.

\section{Conclusion}

DigiFed is on the lookout to create the most impactful mechanism to aid the creation of value and competitive advantage for European SMEs and mid-caps. The analysis of the proposal for the Application Experiment (AE) facilitates the portability assessment for the innovation pathway. While TWIN AE was tested by other initiatives in the past, its relatively recent appearance allows further experimentation in a quest to optimize this instrument according to target stakeholders' needs. In DigiFed's case, the experimentation focuses on fostering cross-border collaboration, which has had limited coverage in the past involvement of DIHs, which are typically working on a regional level. Two recent open calls have created a balanced portfolio of AE types (SINGLE vs TWIN). The smaller companies (1-10 employees) had a consistently higher success 
rate in terms of proposal application to TWIN AE type. Equally, companies with lower digitalisation maturity level are more likely to apply to the collaborative AE (TWIN). The future investigations will consider AEs' implementation progress and sustainable exploitation, as well as the evolution of the funding mechanisms. Authors consider that there is a need for a deeper understanding of the DIH impact and their improved collaboration for the benefit of innovation and digitalisation in Europe's SMEs.

\section{Acknowledgement}

The presented work has received funding from the European Union's Horizon 2020 Research and Innovation program under grant agreement No 761708 (DigiFed). This work was supported by the French National Research Agency in the framework of the "Investissements d'avenir" program (IRT Nanoelec, ANR-10-AIRT-05).

\section{References}

1. Digitising European Industry. Reaping the full benefits of a Digital Single Market, Brussels, 19.4.2016 $\operatorname{COM}(2016) \quad 180 \quad$ final, https://eur-lex.europa.eu/legalcontent/EN/TXT/PDF/?uri=CELEX:52016DC0180\&from=EN (accessed Apr 6, 2021).

2. ICT Innovation for Manufacturing SMEs (I4MS) https://i4ms.eu/ (accessed Apr 6, 2021).

3. Smart Anything Everywhere https://smartanythingeverywhere.eu/ (accessed Apr 6, 2021).

4. Cecchi F., Dario P. (2020) The Experiment Instrument in ECHORD++: Cascade Funding for Small-Scale Research Projects for Facilitating the Introduction of Robotics Technology into Industry. In: Grau A. et al, (eds) Advances in Robotics Research: From Lab to Market. Springer Tracts in Advanced Robotics, vol 132. Springer, Cham.

5. Armengaud E., Peischl B., Priller P., Veledar O. (2019) Automotive Meets ICT-Enabling the Shift of Value Creation Supported by European R\&D. In: Langheim J. (eds) Electronic Components and Systems for Automotive Applications, in Mobility. Springer, Cham.

6. Raposo M. L., Ferreira J.J.M., Fernandes C.I. (2014) Local and cross-border SME cooperation: Effects on innovation and performance, Cooperación local y transfronteriza de las PYME: Efectos sobre la innovación y el desempeño, vol 23, issue 4, 157-165

7. EuroCPS project https://www.eurocps.org/ (accessed Apr 6, 2021).

8. FED4SAE program https://fed4sae.eu/ (accessed Apr 6, 2021).

9. Tetracom project https://www.tetracom.eu/ (accessed Apr 6, 2021).

10. Tetramax project https://www.tetramax.eu/ (accessed Apr 6, 2021).

11. Kljajić Borštnar M., Pucihar A. (2021) Multi-Attribute Assessment of Digital Maturity of SMEs Electronics 10, no. 8: 885. https://doi.org/10.3390/electronics10080885

12. European Union Countries https://europa.eu/european-union/about-eu/countries_en (accessed Apr 6, 2021).

13. European Commission- Directorate-General for Research \& Innovation https://ec.europa.eu/research/participants/data/ref/h2020/grants_manual/hi/3cpart/h2020hi-list-ac_en.pdf (accessed Apr 6, 2021).14. European Commission - Internal Market, Industry, Entrepreneurship and SMEs: SME definition https://ec.europa.eu/growth/smes/sme-definition_en (accessed Apr 6, 2021).

15. A. Crupi, N. Del Sarto, A. Di Minin, G. L. Gregori, D. Lepore, L. Marinelli, and F. Spigarelli, "The digital transformation of SMEs - a new knowledge broker called the digital innovation hub,” Journal of Knowledge Management, vol. 24, no. 6, pp. 1263-1288, 2020. 
16. B. Hinings, T. Gegenhuber, and R. Greenwood, "Digital innovation and transformation: An institutional perspective," Information and Organization, vol. 28, no. 1, pp. 52-61, 2018.

17. Mastering the Digital Innovation Challenge, MIT Sloan Management Review, 07-Mar2017. https://sloanreview.mit.edu/article/mastering-the-digital-innovation-challenge/. (accessed: Jun 9 2021). 